\title{
A Review of Surgical Informed Consent: Past, Present, and Future. A Quest to Help Patients Make Better Decisions
}

\author{
Wouter K. G. Leclercq • Bram J. Keulers • \\ Marc R. M. Scheltinga - Paul H. M. Spauwen • \\ Gert-Jan van der Wilt
}

Published online: 7 April 2010

(C) The Author(s) 2010. This article is published with open access at Springerlink.com

\begin{abstract}
Background Informed consent (IC) is a process requiring a competent doctor, adequate transfer of information, and consent of the patient. It is not just a signature on a piece of paper. Current consent processes in surgery are probably outdated and may require major changes to adjust them to modern day legislation. A literature search may provide an opportunity for enhancing the quality of the surgical IC (SIC) process.

Methods Relevant English literature obtained from PubMed, Picarta, PsycINFO, and Google between 1993 and 2009 was reviewed.

Results The body of literature with respect to SIC is slim and of moderate quality. The SIC process is an underestimated part of surgery and neither surgeons nor patients sufficiently realize its importance. Surgeons are not specifically trained and lack the competence to guide patients through a legally correct SIC process. Computerized programs can support the SIC process significantly but are rarely used for this purpose.

Conclusions IC should be integrated into our surgical practice. Unfortunately, a big gap exists between the
\end{abstract}

W. K. G. Leclercq and B. J. Keulers contributed equally to this work.

W. K. G. Leclercq $(\bowtie) \cdot$ M. R. M. Scheltinga

Department of General Surgery, Máxima Medical Centre, P.O. Box 7777, 5500 MB Veldhoven, The Netherlands

e-mail: wleclercq@hotmail.com

B. J. Keulers · P. H. M. Spauwen

Department of Plastic and Reconstructive Surgery, University

Medical Centre St Radboud, Nijmegen, The Netherlands

G.-J. van der Wilt

Department of Epidemiology and Biostatistics, University

Medical Centre St Radboud, Nijmegen, The Netherlands theoretical/legal best practice and the daily practice of IC. An optimally informed patient will have more realistic expectations regarding a surgical procedure and its associated risks. Well-informed patients will be more satisfied and file fewer legal claims. The use of interactive computer-based programs provides opportunities to improve the SIC process.

\section{Introduction}

Daily surgical practice is characterized by an increased complexity of the operative procedures while time pressure on the outpatient staff continues to increase. Moreover, a patient today tends to demand more extensive information from his/her doctors. Execution of these complicated processes must be legally sound. One way to cope with these developments is to optimize patient education in daily practice through computer-based techniques. A next step is to expand the focus from patient education to surgical informed consent (SIC). This overview provides a descriptive study of this challenging field of surgical practice.

Informed consent (IC) is a legal term that is supported by jurisdiction and international laws and is described as "voluntary authorization, by a patient or research subject, with full comprehension of the risks involved, for diagnostic or investigative procedures, and for medical and surgical treatment" (year introduced: 1973 (1971), http://www. ncbi.nlm.nih.gov/mesh/68007258?ordinalpos=1\&itool=Entrez System2.PEntrez.Mesh.Mesh_ResultsPanel.Mesh_RVDoc Sum). Basic elements of IC are "preconditions," "information," and "consent." Preconditions for proper IC include the patient's competence and voluntariness. The information provided must be adequate and comprehensible. The consent of a patient authorizes the (surgical) procedure that will be performed. 
The system of the patient giving consent for an invasive procedure or operation (surgical IC or SIC) has been common practice for many years. Providing appropriate preoperative information to a surgical patient is dictated by law and may prevent litigation. In spite of major developments in the law, information technology, and patients wishes, procedural aspects of SIC have not changed sufficiently over the last few decades in most hospitals. Surgeons prepare their patients randomly, and the quality of information will probably differ extensively. Patients are supposed to give SIC with (or without) written information.

Currently, patient education and patient-oriented care are important topics. Nevertheless, the literature on the quality of SIC is scarce. The initial concepts and laws on SIC are outdated and have been replaced by up-to-date legislation. Our hypothesis is that daily practice is still based on old habits and therefore is not as good as necessary to meet current needs. The aim of this review was to describe the pertinent literature concerning SIC and to provide suggestions to improve the SIC process in daily practice.

\section{Methods}

We were interested in identifying hard data in the literature that could be used to enhance the quality of the SIC process. Our objectives were to answer the following questions: (1) What are the fundamental elements of an adequate SIC process? (2) What is the current state of the SIC process? (3) How can we improve the quality of the SIC process in the future?

\section{Search strategy}

Relevant literature was identified in PubMed, Picarta, PsycINFO, and Google using the keywords/Mesh terms "informed consent," "surgical procedures," "operative," "patient education," "mental competency," and "history."
Searches were performed by two surgical trainees (WL and BK) independently. All selected articles were scanned for relevant references or "related articles" (PubMed). Selection criteria included language (English publications or abstracts) and time period (January 1993-January 2009, with the exception of the legal cases).

Main results

A total of 2,952 articles was identified using the Mesh terms "surgical procedures" and "informed consent," of which 2,567 were in English. Most of these articles were not related to the present study questions listed above, as operative procedures were tested which required an IC. Only a limited number of articles focused on the SIC process itself. Eventually, 175 articles were selected directly, through references, or a related article search. Of this body of literature, 71 articles met our inclusion criteria. Meta-analysis of these articles was not possible because the studies differed in study design, tests used, and outcome measurement.

\section{History of surgical informed consent}

In medieval times doctors asked for a "hold harmless document" aimed at releasing them from any future responsibility to the patient or family in the event anything adverse happened following therapy. This pro corpore mortuoto can be found in Italian, French, and Middle East archives as early as the 14th century and is considered an early precursor of IC, although its purpose was to protect the doctor and not the patient [1-3]. The initial concept of current IC legislation developed in later centuries from case-related litigation into a standard practice (Fig. 1). Some bizarre landmark cases may be identified and are worth mentioning in the present overview. In the 18th century, a patient sued his doctor for refracturing his leg and experimenting with a novel external fixating mechanism without informing the patient or
Fig. 1 Landmarks in the history of the IC process: a timetable

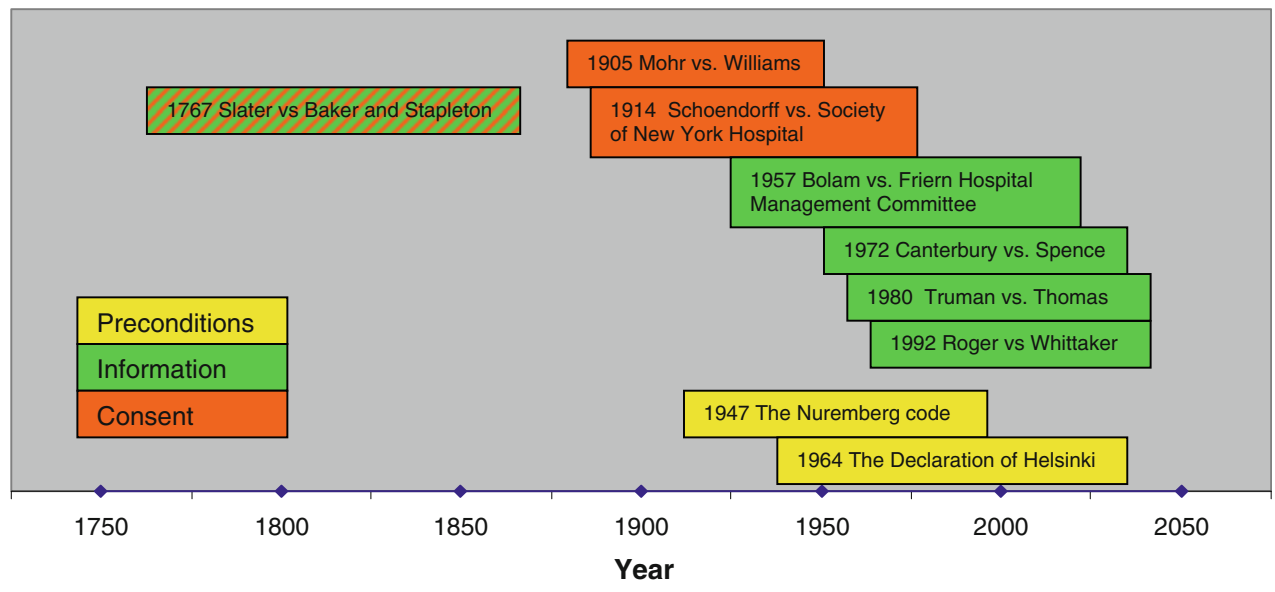


obtaining approval. This 1767 Slater vs. Baker and Stapleton trial was the first example of an IC case [4, 5]. The concept of IC was used in an 1845 novel by Edgar Allen Poe. A patient was asked for permission for an experimental therapy just before his death (Fig. 2) [6,7].

The fundamentals of today's practice of SIC gained more structure at the beginning of 20th century, especially after the development of anesthesia and more invasive surgery (Fig. 1). In Mohr vs. Williams in 1905, a woman agreed to an operation on her right ear [8]. However, during the operation the surgeon found her left ear in the need of a repair. He was subsequently sued and convicted because he had not proceeded according to the preoperative agreement. The judge called this agreement a contract that authorizes the physician to operate only to the extent of the consent given [9]. In Schoendorff vs. Society of New York Hospital in 1914, Justice Benjamin Cardozo (Fig. 3) became famous for his judgment in the following case. A woman had consented to an abdominal examination under anesthesia but not to an operation [10]. Nevertheless, the surgeon removed a tumor that eventually led the patient to file a law suit. Cardozo's opinion has become one of the most basic elements in the concept of SIC development: "Every human being of adult years and sound mind has a right to determine what shall be done with his own body, and a surgeon who performs an operation without the patient's consent commits an assault for which he is liable in damages" [11-13]. A patient should be viewed as a person who has the right of bodily self-determination $[5,12]$.

After the Second World War, there was a strong public reaction to the cruelties committed by Nazi concentration camp "doctors" who performed horrible tests on "patients" without prior information or approval. A code was written as a direct result of the Nuremberg trials (U.S.A. vs. Karl Brandt et al.). This "Nuremberg Code" was an important step in the development of the IC process in trials (Fig. 4). It consisted of ten preconditions any human research study had to fulfill. Interestingly, the first governmental instruction for IC in trials originated in Germany and was written in 1900 [14]. Later on in 1964, The World Health Organization set the Declaration of Helsinki with 22 preconditions for human research. The 1957 case Salgo vs. Leland Stanford, Jr. University Board of Trustees introduced the term "informed consent," and this term was accepted in Natanson vs. Kline in 1960 [12, $15,16]$.

At the same time, a development occurred in the domain of "information." The 1957 UK case Bolam vs. Friern Hospital Management Committee focused on which risks should be discussed with a surgical patient [17]. This doctor-centered view resulted in a reasonable standard: Any surgeon should tell what other surgeons also tell their patients, a principle known as the Bolam principle [11]. However, the 1972 Canterbury vs. Spence case determined that all risks and alternatives of a procedure have to be explained [18]. This trial clearly demonstrated a shift from the doctors' point of view toward the patients' point of view as the standard of IC: the "reasonable patient standard" $[11,12,19,20]$. Subsequently, the Australian High Court overruled the Bolam principle in the 1992 Roger vs. Whittaker case of a woman losing sight in her good eye after being operated on her diseased eye [21]. Although the risk of this happening was a mere 1:14,000, the court ruled that the surgeon should have informed the woman of the risk as she had apparently asked for this information. On the other hand, the doctor had considered this low risk not relevant $[11,20]$. Although not totally abandoned, the "reasonable doctor standard" has become a secondary standard next to the "reasonable patient standard" in most countries [21]. Since the 1980 Truman vs. Thomas case, information provided in an IC process must also include the risks of "not acting or postponing" [22]. In this case, a Pap smear was refused by a woman who claimed not to know the associated risks, i.e., not detecting cancer in time for curative treatment [7].

Dutch legislators as well as governments from various other Western countries have realized that their legislation was out of date. Based on cases such as those mentioned above, several adjustments have led to the 1995 Dutch Medical Treatment Contract Act in which all elements of IC are present, including preconditions, information, and consent. Although legislation differs widely between countries, these "basic elements" are consistent in the Western world.

\section{Present practice of surgical informed consent}

\section{Current elements of SIC}

Based on historical cases and legislation, IC is supported by three cornerstones: "preconditions," "information," and "consent" (Fig. 5).

Preconditions include competence and voluntariness. A patient is a person who has a right of self-determination. $\mathrm{He} / \mathrm{she}$ must be able to make decisions about his/her own body and must be able to decide freely without being influenced by others.

The second cornerstone is information. According to the 1995 WHO declaration on the promotion of patients rights, patients have the right to be fully informed about their health status, including the medical facts about their condition; about the proposed medical procedures, together with the potential risks and benefits of each procedure; about alternatives to the proposed procedures, including the effect of nontreatment; and about the diagnosis, prognosis, 
Fig. 2 American Review: A Whig Journal of Politics, Literature, Art, and Science (December 1845); publication of Edgar Allen Poe's "The fact in the case of M. Valdemar." Available at http://digital. library.cornell.edu/cgi/t/text/ text-idx? $=\mathrm{amwh} ; \mathrm{idno}=\mathrm{amw}$ h0002-6
1845.]

The Facts of $M$. Valdemar's Case.

561

THE FACTS OF M. VALDEMAR'S CASE.

B $\mathrm{E}$ D A $\mathrm{R}$ A. P O E.

Or course I shall not pretend to consider it any matter for wonder, that the extraordinary case of M. Valdemar has excited discussion. It would have been a miracle had it not-especially under the circumstances. Throngh the desire of all parties concerned to keep the affair from the public, at least for the present, or until we had farther opportunities for investigation - through our endeavors to effect this-a garbled or exaggerated account made its way into society, and became the source of many unpleasant misrepresentations, and, very natu. rally, of a great deal of disbelief.

It is now rendered necessary that I give the facts-as far as I comprehend them myself. They are, succinctly, these :

My attention, for the last three years, had been repeatedly drawn to the subject of Mesmerism; and, about nine months ago, it occurred to me, quite suddenly, that in the series of experiments made hitherto, there had been a very remarkable and most unaccountable omission:-no person had as yet been mesmerized in articulo mortis. It remained to be seen, first, whether, in such condition, there existed in the patient any susceptibility to the magnetic influence; secondly, whether, if any existed, it was impaired or increased by the condition; thirdly, to what extent, or for how long a peried, the encroachments of Death might be arrested by the process. There were other points to be ascertained, but these most excited my curiosity - the last in especial, from the immensely important character of its consequences.

In looking around me for some subject by whose means 1 might test these parti. culars, I was brought to think of my friend, M. Ernest Valdemar, the well-known compiler of the "Bibliotheca Forensica," and author (under the nom de plume of Issachar Marx) of the Polish versions of "Wallenstein" and "Gargantua." M. Valdemar, who has resided principally at Harlaem, N. Y., since the year 1839, is (or was) particularly noticeable for the extreme spareness of his person-his lower limbs much resembling those of John Randolph; and, also, for the whitevoL. II.-No. vI. ness of his whiskers, in violent contrast to the blackness of his hair-the latter, in consequence, being very generally mistaken for a wig. His temperament was markedly nervous, and rendered him a good subject for mesmeric experiment. On two or three occasions I bad put him to sleep with little difficulty, but was disappointed in other results which his peculiar constitution had naturally led me to anticipate. His will was at no period positively, or thoroughly, under my control, and in regard to clairvoyance, I could accomplish with him nothing to be relied upon. I always attributed my failure at these points to the disordered state of his health. For some months previous to my becoming acquainted with him, his physicians had declared him in a confirmed phthisis. It was his custom, indeed, to speak calmly of his approaching dissolution, as of a matter neither to be avoided not regretted.

When the ideas to which I have alluded first occurred to me, it was of course very natural that $I$ should think of M. Valdemar. I knew the steady philosophy of the man too well to apprehend any scruples from him; and he had no relatives in America who would be likely to interfere. I spoke to him frankly upon the subject; and, to my surprise, his interest seemed vividly excited. I say to my surprise; for, although he had always yielded his person freely to my experiments, he had never before given me any tokens of sympathy with what I did. His disease was of that character which would admit of exact calculation in respect to the epoch of its termination in death; and it was fually arranged between us that he would send for me about twenty-four hours before the period announced by his physicians as that of his decease.

It is now rather more than seven months since I received from $M$. Valdemar, himself, the subjoined note :

"Mr deAr P-,

"You may as well come noto. Dand $\mathrm{F}$ - are agreed that I cannot bold out beyond to-morrow midnight; and I think they have hit the time very nearly.

"VALDEMAR," and progress of treatment [23]. All this information must be disclosed by the surgeon to enable the patient his/ her right of self-determination. A well-defined care plan incorporating the surgeon's advice should be discussed and it must be verified that the patient understands this information. 


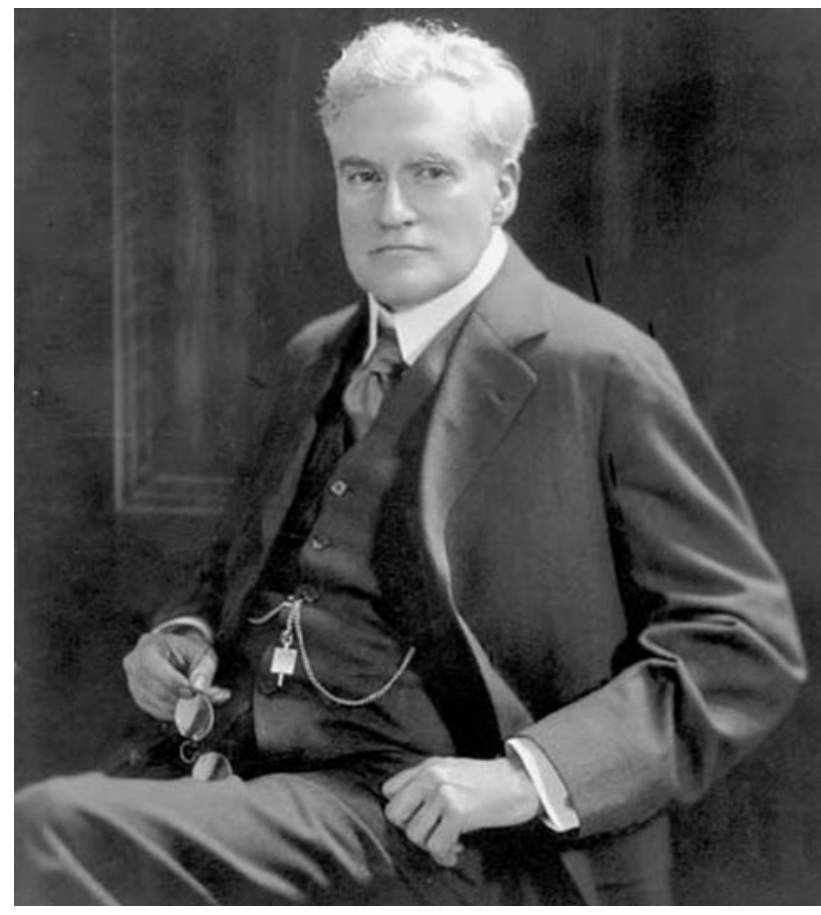

Fig. 3 Cardozo, Benjamin Nathan. Online photograph from the Encyclopædia Britannica. Available at http://www.britannica.com/eb/ art-96738

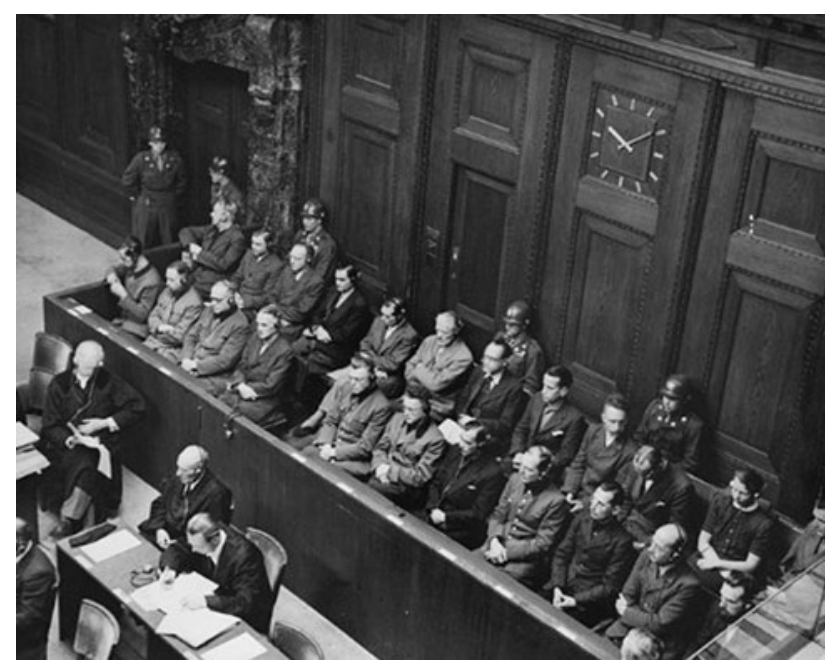

Fig. 4 Nuremberg Trial: the 23 defendants in dock during the doctors' trial. Available at http://www.law.umkc.edu/faculty/projects/ ftrials/nuremberg/docdef.jpg

The third cornerstone is consent: registration of the patient's decision and (written) consent [11, 24, 25].

Informed consent is often given by the patient during a preoperative consult with a consultant, a resident, or a specialized nurse. The information associated with a surgical procedure can be exchanged verbally, in writing, by video, or by computer technology. In this respect, large differences exist between countries. The US demands a

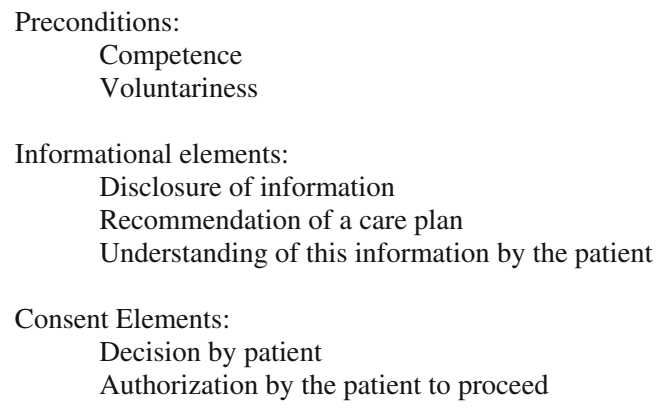

Fig. 5 The elements of IC

patient signature, whereas a note in the patient chart is sufficient in the UK. In the Netherlands, doctors are not strictly required to obtain written consent [26].

\section{Preconditions}

As a routine, the patient's competence is only "checked" in a general sense and deemed appropriate if communication with a patient is "normal" [27]. Only if the patient is officially "incompetent" will a legally appointed surrogate decision maker or an other representative in accordance with the law be allowed to decide for the patient [27]. However, a normal intelligence per se does not necessarily mean that a patient is really competent. Recently, Appelbaum [28] reviewed the literature on patient competence. A group of patients with known cognitive disease and patients with cancer demonstrated variable outcomes on competence tests. Lower scores were found in people of older age and limited education. The number of "incompetent" patients was higher than expected. Surprisingly, the doctor's ability to differentiate between competent and incompetent was not better than throwing a dice [28].

On the other hand, even patients who are objectively deemed competent may be ignorant. They frequently do not know the process of SIC and do not know their rights, which results in wrong beliefs [29, 30]. Only $40 \%$ of the patients think that the IC paper confirms their wishes [29]. Interestingly, they usually do not feel the need for more information and their actual knowledge of the benefits and risks involved remains poor [31-35]. In contrast, when asked what information they would like to have, they indicate that they would like more information than they actually receive [36].

Several misconceptions also exist with respect to voluntariness. One study reveals that $46 \%$ of patients in the study were under the impression that the major goal of an IC is to protect the hospital from litigation. In addition, $68 \%$ of the patients were convinced that the IC process gives the doctor control of what is going to happen [29]. 
Information elements

Literature on patient education is extensive and is usually focused on informing patients in a general sense. On the other hand, studies on information in relation to the IC process are scarce. Results consistently demonstrate that neither doctors nor patients are well prepared for all elements of the IC process [19, 20, 30, 37-42]. Residents are frequently "in charge" of the IC process but do not know what to tell a patient and do not perform well in tests on IC and medical law [25, 37, 43]. In contrast, they are more capable in informing the patient of benefits of the surgical procedure than they are giving information about risks or alternatives [37]. Interestingly, $21 \%$ of patients in one study reported that they received most information from sources outside the hospital [44].

The way information is presented greatly influences what a patient remembers. Oral information is retained very poorly, and patients tend to forget crucial parts of information such as alternative treatment options [41, 45]. This will lead to false-negative feelings, particularly in patients with a IQ below average, age over 60 , a tendency to somatization, or a poor perceived control [44]. On the other hand, betterinformed patients will have more realistic expectations, higher satisfaction, and demonstrate more treatment cooperation [46]. A recent study reveals that a great difference exists between the points of view of surgeons and patients regarding relevance of information and what should be told or not told [36]. Another study demonstrates that patients are not interested in the IC form that is used, and two thirds of the patients do not read it carefully [44].

Studies on the patient's comprehension of information are rare. Analyses of tapes of IC indicate that various elements of the surgical procedure are discussed in $71 \%$ of the cases. The assessment of whether the patients actually understand this information is performed in only $1.5 \%$ of the cases $[41,47]$ !

\section{Consent elements}

Studies focusing on the consent element indicate that consent forms are not composed very well [48, 49]. Readability is poor, and only a minority are written on a 12-year-old reading level, which is best practice [48-50]. More than half of all IC forms are filled out incorrectly [19, 51]. One retrospective study shows that the consent forms cannot be retrieved in $7.7 \%$ of the cases [19].

\section{Future improvements of surgical informed consent}

Substantial weaknesses and omissions of SIC are evident and the current elements of the SIC process are largely neglected in daily practice $[19,20,27-35,37-39,41,44$, $45,47,48]$. Preconditions are ignored, information is incomplete, and the consent itself is not an accurate reflection of the patient's authorization. SIC apparently is not a popular part of the doctor-patient relationship, and presumably both parties are guilty. In the media surgeons are blamed for making mistakes and people are encouraged to "sue for every fault their surgeons make," leading to an increase in medicolegal claims [35]. However, it should be realized that most legal cases are not due to failures in treatment but due to failure in communication [11, 35]. Discrepancies between expected and achieved results $(55 \%)$ and faulty information $(30 \%)$ are the main reasons for patients to file claims. In contrast to what one would expect, most complaints are generated after minor elective operations (70\%) [52].

Articles analyzing the quality of the SIC forms and their performances in court were not identified in the present overview. Circumstantial evidence, however, supports the view that ample opportunities are available to improve not only these forms but the whole SIC process. An IC form is inadequate if it deals only with the IC form itself while omitting the incorporation of the information process or the quality of the total process. Several cases based on faulty forms resulted in successful claims: no documented alternatives, risks, or IC form at all [53]. Hence, a nonstandardized way of informing a patient of the risks of complications inherently results in a vulnerable position for the surgeon [25]. Both surgeons and their patients must realize that an improved and standardized IC process leads to more realistic expectations. Better-informed patients are more satisfied, have a higher commitment to their treatment, and demonstrate less tendency toward filing legal claims [53]. Both groups obviously have a lot to gain from an optimized SIC process.

Strengthening the surgeon's education on SIC might look like an easy way to optimize the SIC process. However, training doctors, or specialised nurses, aimed at improving their skills in the SIC process is not very successful and this approach is very time consuming [38, 54-56].

A computer may aid the doctor help his patient receive high-quality SIC for elective procedures. It should be realized that computer programs do not undermine the doctor-patient relationship but are potentially valuable [40, 42]. The SIC should therefore ideally be performed using an integrated interactive computer program $[40,42,56]$. As most surgeons prefer to spend their time on surgery itself, they must consider introducing computer technology as an aid in the SIC process in daily surgical practice.

A number of validated tests have been developed to check the patient's competence. A recent study demonstrates that the outcome of such a test is almost as 
Table 1 Overview of randomized controlled trials focused on IC

\begin{tabular}{|c|c|c|c|c|c|c|c|}
\hline Author & Journal & $\begin{array}{l}\text { Year of } \\
\text { publication }\end{array}$ & Specialism & Country & $N$ & Study groups & $\begin{array}{l}\text { Outcome in favor of } \\
\text { study group(s) }\end{array}$ \\
\hline $\begin{array}{l}\text { Armstrong } \\
\text { et al. [11] }\end{array}$ & Br J Plast Surg & 1997 & Plast Surg & UK & 269 & Oral vs. oral and written information & Oral and written \\
\hline $\begin{array}{l}\text { Deyo et al. } \\
\text { [64] }\end{array}$ & Med Care & 2000 & Neuro/Ort & USA & 393 & $\begin{array}{l}\text { Oral and written information vs. pc- } \\
\text { based video }\end{array}$ & pc-based video \\
\hline $\begin{array}{l}\text { Chan et al. } \\
{[61]}\end{array}$ & $\begin{array}{l}\text { Arch Otolaryngol } \\
\text { Head Neck Surg }\end{array}$ & 2002 & $\begin{array}{l}\text { Ent/Gen } \\
\text { surg }\end{array}$ & Canada & 125 & $\begin{array}{l}\text { Oral vs. oral and written information } \\
\text { with figures }\end{array}$ & $\begin{array}{l}\text { Oral and written with } \\
\text { figures }\end{array}$ \\
\hline $\begin{array}{l}\text { Mason et al. } \\
\text { [69] }\end{array}$ & $B J O G$ & 2003 & Gyn & UK & 31 & Oral vs. oral and video information & Oral and video \\
\hline $\begin{array}{l}\text { Rossi et al. } \\
\text { [73] }\end{array}$ & Arthroscopy & 2005 & Ort & USA & 150 & Oral vs. oral and video information & Oral and video \\
\hline $\begin{array}{l}\text { Danino et al. } \\
\text { [62] }\end{array}$ & $\begin{array}{l}\text { Plast Reconstr } \\
\quad \text { Surg }\end{array}$ & 2006 & Plast Surg & France & 60 & Oral vs. oral and video information & Oral and video \\
\hline $\begin{array}{l}\text { Moseley et al. } \\
\text { [71] }\end{array}$ & Br J Ophthalmol & 2006 & Oph & USA & 90 & $\begin{array}{l}\text { Oral vs. oral and dia or video } \\
\text { information }\end{array}$ & Oral and dia or video \\
\hline $\begin{array}{l}\text { Keulers et al. } \\
\text { [66] }\end{array}$ & $\begin{array}{l}\text { Patient Educ } \\
\text { Couns }\end{array}$ & 2007 & Plast Surg & Netherlands & 113 & $\begin{array}{l}\text { Oral and written vs. pc-based } \\
\text { information }\end{array}$ & pc-based \\
\hline $\begin{array}{l}\text { Masood et al. } \\
{[70]}\end{array}$ & $B J U$ Int & 2007 & Uro & UK & 45 & Oral vs. oral and written information & Oral only \\
\hline $\begin{array}{l}\text { Eggers et al. } \\
\text { [42] }\end{array}$ & Obesity & 2007 & Gen surg & Germany & 40 & $\begin{array}{l}\text { Oral and written information vs. Oral, } \\
\text { written and pc-based information }\end{array}$ & $\begin{array}{l}\text { Oral, written, and pc- } \\
\text { based information }\end{array}$ \\
\hline $\begin{array}{l}\text { Bollschweiler } \\
\text { et al. [43] }\end{array}$ & Ann Surg & 2008 & Gen surg & Germany & 76 & $\begin{array}{l}\text { Oral and written information vs. Oral, } \\
\text { written and pc-based information }\end{array}$ & $\begin{array}{l}\text { Oral, written, and pc- } \\
\text { based information }\end{array}$ \\
\hline
\end{tabular}

$N$ number of patients; Plast Surg plastic surgery; Neuro neurosurgery; Ort orthopedics; Ent ear nose throat; Gen Surg general surgery; Gyn gynecology; Oph ophthalmology; Uro urology

consistent as an expert opinion [28]. Examples of such validated tests are the Mini-Mental State Examination, the MacArthur Competence Assessment Tool, the Decision Evaluation Scales (DES), and the MacCaT-T [23, 28, 57]. All these tests are suitable for computer-based programs.

An effective way of informing patients about their surgical procedure might be by using computer-based information [23, 51, 58]. The more interactive information is provided, the more a patient remembers (Table 1) $[11,13$, $24,34,40,42,58-76]$. Nonetheless, the amount of information that is transferred during a preoperative consultation in an outpatient environment can be overwhelming [41]. If transfer of information is adjusted to the patient's own speed and wishes in an interactive setting, he/she tends to comprehend more and will have better recapitulation [40-42, 66]. Surprisingly, patients with limited computer experience, a low educational level, or of old age appear to benefit [40, 52, 77, 78]. Validated tests have been developed to check if the patient actually understands the information [28, 57]. Using this approach, doctors buy time that can be used for discussing specific procedural details, personal questions, or emotions.

Recording the SIC process is of growing importance in medicolegal cases. Computer-based interactive IC programs have the advantage of recording every step a patient takes in gaining information [35]. In various empirical studies the consent form is replaced by a recorded patient authorization through a computer-based interface [40, 42, 79]. This approach focuses on only the consent part of the process; it does not check whether a patient is competent or understands the information sufficiently. Basically, it is nothing more than a digitized IC form [40, 42].

More research is necessary to improve the SIC process in daily practice. We have recently developed a SIC program based on the best available practice as described in this review. This program uses an online interface that can be used at home or at the hospital for patients needing more guidance. In this program, patients are first screened for their competence. Then basic information on their specific surgical procedure is provided through text, audio information, and flash movies. Many words are highlighted (hyperlinked) and can be selected for extra information. Patients can also select other options for extra information on logistic, medical, or legal items. The patient's level of knowledge is checked at the end of this information part. If insufficient information is retained, these items are repeated because basic information must be trustworthy before the consent part starts. The consent part of SIC provides an overview of the surgical procedure, its risks, and alternatives. The patient or the surgeon can print out the form and both can sign it after all remaining questions are answered. This program will be evaluated on a national level in an 
upcoming trial and may ideally be integrated into our future practice.

\section{Practice implication for an adequate IC process}

\section{General}

1. Professionalize and structure your SIC and do not rely on good intent.

2. Focus on all operations, not just on the major operations.

3. Make patients and doctors aware of the importance of an adequate SIC.

4. Teach your patient what IC is.

5. Make sure the patient realizes he/she is in control and not the doctor.

6. Do not be afraid to use an interactive computer to help you, the doctor, and the patient.

\section{Competence}

Check your patient's competence and do not count on your clinical insight.

\section{Information}

1. Provide locally adapted information and try not to use general information.

2. Check if your patient understands your plan of operation, e.g., ask the patient to repeat the information.

3. Check if your patient understands the risks and the alternatives.

\section{Consent}

Register the SIC process in detail using an adequate IC form, and check that it is filled in correctly and store it in a safe place.

\section{Research}

Check for more research to be published as SIC is not a fixed format but a developing area of medicine.

Acknowledgments We thank Professor H. D. C. Roscam Abbing, Emeritus Professor of Department of Law, Economics and Governance, University Medical Centre Utrecht (Utrecht, The Netherlands) for her valuable contributions to early versions of this article. The study was supported by the Stichting Hart- en Vaatziekten Zuid-Nederland.

Open Access This article is distributed under the terms of the Creative Commons Attribution Noncommercial License which permits any noncommercial use, distribution, and reproduction in any medium, provided the original author(s) and source are credited.

\section{References}

1. Ajlouni KM (1995) History of informed medical consent. Lancet 346(8980):980

2. Baron JH (1996) History of informed medical consent. Lancet 347(8998):410

3. Rothman DJ (1995) History of informed medical consent. Lancet 346(8990): 1633

4. Eng Rep. Slater vs. Baker and Stapleton, 1767 (Slater vs. Baker and Stapleton 95 Eng Rep. 860 (k.b. 1767))

5. Curran WJ, Hall MA, Kaye DH (1990) Health care law, forensic science, and public policy, 4th edn. Little, Brown and Company, Boston

6. Altschuler EL (2003) Informed consent in an Edgar Allen Poe tale. Lancet 362(9394): 1504

7. Poe EA (1845) The fact in the case of M. Valdemar. Am Rev: Whig J Polit Lit Art Sci II(VI). http://digital.library.cornell. edu/cgi/t/text/text-idx?c=amwh;idno=amwh0002-6

8. Supreme Court of Minnesota (1905) Mohr v. Williams (104 N.W. 12 Supreme Court of Minnesota)

9. Recent Decisions: Tort. assault and battery. Unauthorized surgical operation constitutes "assault and battery." (1927) Virginia Law Rev 13(6):505. http://www.jstor.org/pss/1064659

10. N.E. Schoendorff v. Society of New York Hospital, 1914 (106N.E. 93 (N.Y. 1914))

11. Armstrong AP, Cole AA, Page RE (1997) Informed consent: are we doing enough? Br J Plast Surg 50(8):637-640

12. Katz J (1998) Reflections on informed consent: 40 years after its birth. J Am Coll Surg 186(4):466-474

13. Langdon IJ, Hardin R, Learmonth ID (2002) Informed consent for total hip arthroplasty: does a written information sheet improve recall by patients? Ann R Coll Surg Engl 84(6):404-408

14. Vollmann J, Winau R (1996) Informed consent in human experimentation before the Nuremberg code. BMJ 313(7070): 1445-1449

15. P. Salgo v. Leland Stanford Jr. University Board of Trustees, 1957 (317 P.2d 170)

16. P. Natanson vs. Kline, 1960 (350 P.2d 1093)

17. WLR Bolam vs. Friern Hospital Management Committee, 1957 (1 WLR 583)

18. F. Canterbury vs. Spence, 1972 (464 F.2d 772 (d.c. 1972))

19. Issa MM, Setzer E, Charaf C et al (2006) Informed versus uninformed consent for prostate surgery: the value of electronic consents. J Urol 176(2):694-699

20. Skene L, Smallwood R (2002) Informed consent: lessons from Australia. BMJ 324(7328):39-41

21. Kastelein WR (1998) [Informed consent and medical liability: jurisprudence 1994-1998. Tijdschr Gezondhd 22:134-146 [in Dutch]

22. P. Truman vs. Thomas, 1980 (611 P.2d 902 (Cal 1980))

23. World Health Organization Staff (1995) Promotion of the Rights of Patients in Europe. In: Proceedings of a WHO Consultation

24. Ashraff S, Malawa G, Dolan T et al (2006) Prospective randomised controlled trial on the role of patient information leaflets in obtaining informed consent. ANZ J Surg 76(3):139-141

25. Pleat JM, Dunkin CS, Davies CE et al (2004) Prospective survey of factors affecting risk discussion during consent in a surgical specialty. Br J Surg 91(10):1377-1380

26. Verbogt S (2003) Hoofdstukken over gezondheidsrecht (chapters in health law), 9th edn. Wolters-Noordhoff, Groningen, The Netherlands. ISBN:9068905759 
27. Bernat JL, Peterson LM (2006) Patient-centered informed consent in surgical practice. Arch Surg 141(1):86-92

28. Appelbaum PS (2007) Clinical practice. Assessment of patients' competence to consent to treatment. N Engl J Med 357(18):18341840

29. Akkad A, Jackson C, Kenyon S et al (2006) Patients' perceptions of written consent: questionnaire study. BMJ 333(7567):528

30. Schouten B, Hoogstraten J, Eijkman M (2002) Dutch dental patients on informed consent: knowledge, attitudes, self-efficacy and behaviour. Patient Educ Couns 46(1):47-54

31. Ghulam AT, Kessler M, Bachmann LM et al (2006) Patients' satisfaction with the preoperative informed consent procedure: a multicenter questionnaire survey in Switzerland. Mayo Clin Proc 81(3):307-312

32. Godwin Y (2000) Do they listen? A review of information retained by patients following consent for reduction mammoplasty. Br J Plast Surg 53(2):121-125

33. Kriwanek S, Armbruster C, Beckerhinn P et al (1998) Patients' assessment and recall of surgical information after laparoscopic cholecystectomy. Dig Surg 15(6):669-673

34. Pesudovs K, Luscombe CK, Coster DJ (2006) Recall from informed consent counselling for cataract surgery. J Law Med 13(4):496-504

35. Shamsian N, Southern SJ, Wilkinson S et al (2005) What is the medicolegal implication of a Web-based three-dimensional interactive virtual reality plastic surgery package? Plast Reconstr Surg 116(6):1839-1840

36. Keulers BJ, Scheltinga MR, Houterman S et al (2008) Surgeons underestimate their patients' desire for preoperative information. World J Surg 32(6):964-970

37. Angelos P, Darosa DA, Bentram D et al (2002) Residents seeking informed consent: are they adequately knowledgeable? Curr Surg 59(1):115-118

38. Leeper-Majors K, Veale JR, Westbrook TS et al (2003) The effect of standardized patient feedback in teaching surgical residents informed consent: results of a pilot study. Curr Surg 60(6):615-622

39. Soin B, Smellie WA, Thomson HJ (1993) Informed consent: a case for more education of the surgical team. Ann R Coll Surg Engl 75(1):62-65

40. Bollschweiler E, Apitzsch J, Obliers R et al (2008) Improving informed consent of surgical patients using a multimedia-based program? Results of a prospective randomized multicenter study of patients before cholecystectomy. Ann Surg 248(2):205-211

41. Brezis M, Israel S, Weinstein-Birenshtock A et al (2008) Quality of informed consent for invasive procedures. Int $\mathrm{J}$ Qual Health Care 20(5):352-357

42. Eggers C, Obliers R, Koerfer A et al (2007) A multimedia tool for the informed consent of patients prior to gastric banding. Obesity (Silver Spring) 15(11):2866-2873

43. McGaughey I (2004) Informed consent and knee arthroscopies: an evaluation of patient understanding and satisfaction. Knee 11(3):237-242

44. Lavelle-Jones C, Byrne DJ, Rice P et al (1993) Factors affecting quality of informed consent. BMJ 306(6882):885-890

45. Keating NL, Weeks JC, Borbas C et al (2003) Treatment of early stage breast cancer: do surgeons and patients agree regarding whether treatment alternatives were discussed? Breast Cancer Res Treat 79(2):225-231

46. Kessler TM, Nachbur BH, Kessler W (2005) Patients' perception of preoperative information by interactive computer programexemplified by cholecystectomy. Patient Educ Couns 59(2):135140

47. Braddock CH III, Edwards KA, Hasenberg NM et al (1999) Informed decision making in outpatient practice: time to get back to basics. JAMA 282(24):2313-2320
48. Bottrell MM, Alpert H, Fischbach RL et al (2000) Hospital informed consent for procedure forms: facilitating quality patient-physician interaction. Arch Surg 135(1):26-33

49. Hopper KD, TenHave TR, Tully DA et al (1998) The readability of currently used surgical/procedure consent forms in the United States. Surgery 123(5):496-503

50. Paasche-Orlow MK, Taylor HA, Brancati FL (2003) Readability standards for informed-consent forms as compared with actual readability. N Engl J Med 348(8):721-726

51. Edwards AG, Weale AR, Morgan JD (2005) Informed consent in renal transplantation. Postgrad Med J 81(953):188-190

52. Krause HR, Bremerich A, Rustemeyer J (2001) Reasons for patients' discontent and litigation. J Craniomaxillofac Surg 29(3): 181-183

53. Baum N (2006) Informed consent-more than a form. J Med Pract Manag 22(3):145-148

54. Guadagnoli E, Soumerai SB, Gurwitz JH et al (2000) Improving discussion of surgical treatment options for patients with breast cancer: local medical opinion leaders versus audit and performance feedback. Breast Cancer Res Treat 61(2):171-175

55. Steinemann S, Furoy D, Yost F et al (2006) Marriage of professional and technical tasks: a strategy to improve obtaining informed consent. Am J Surg 191(5):696-700

56. Dimond B (2002) Legal aspects of consent 22: nurses' position when obtaining consent. Br J Nurs 11(4):281-283

57. Stalmeier PF, Roosmalen MS, Verhoef LC et al (2005) The decision evaluation scales. Patient Educ Couns 57(3):286-293

58. Edwards MH (1990) Satisfying patients' needs for surgical information. Br J Surg 77(4):463-465

59. Askew G, Pearson KW, Cryer D (1990) Informed consent: can we educate patients? J R Coll Surg Edinb 35(5):308-310

60. Brown TF, Massoud E, Bance M (2003) Informed consent in otologic surgery: prospective study of risk recall by patients and impact of written summaries of risk. J Otolaryngol 32(6):368-372

61. Chan Y, Irish JC, Wood SJ et al (2002) Patient education and informed consent in head and neck surgery. Arch Otolaryngol Head Neck Surg 128(11):1269-1274

62. Danino AM, Lile A, Moutel G et al (2006) Visual documentation of oral consent: a new method of informed consent before major gigantomastia reduction for an illiterate population. Plast Reconstr Surg 117(4):1370-1371

63. Dawes PJ, O'Keefe L, Adcock S (1993) Informed consent: using a structured interview changes patients' attitudes towards informed consent. J Laryngol Otol 107(9):775-779

64. Deyo RA, Cherkin DC, Weinstein J et al (2000) Involving patients in clinical decisions: impact of an interactive video program on use of back surgery. Med Care 38(9):959-969

65. Hermann M (2002) 3-dimensional computer animation-a new medium for supporting patient education before surgery. Acceptance and assessment of patients based on a prospective randomized study - picture versus text. Chirurg 73(5):500-507

66. Keulers BJ, Welters CF, Spauwen PH et al (2007) Can face-to-face patient education be replaced by computer-based patient education? A randomised trial. Patient Educ Couns 67(1-2):176-182

67. Layton S, Korsen J (1994) Informed consent in oral and maxillofacial surgery: a study of the value of written warnings. Br J Oral Maxillofac Surg 32(1):34-36

68. Makdessian AS, Ellis DA, Irish JC (2004) Informed consent in facial plastic surgery: effectiveness of a simple educational intervention. Arch Facial Plast Surg 6(1):26-30

69. Mason V, McEwan A, Walker D et al (2003) The use of video information in obtaining consent for female sterilisation: a randomised study. BJOG 110(12):1062-1071

70. Masood J, Hafeez A, Wiseman O et al (2007) Informed consent: are we deluding ourselves? A randomized controlled study. BJU Int 99(1):4-5 
71. Moseley TH, Wiggins MN, O’Sullivan P (2006) Effects of presentation method on the understanding of informed consent. $\mathrm{Br} \mathrm{J}$ Ophthalmol 90(8):990-993

72. O'Neill P, Humphris GM, Field EA (1996) The use of an information leaflet for patients undergoing wisdom tooth removal. Br J Oral Maxillofac Surg 34(4):331-334

73. Rossi MJ, Guttmann D, MacLennan MJ et al (2005) Video informed consent improves knee arthroscopy patient comprehension. Arthroscopy 21(6):739-743

74. Shurnas PS, Coughlin MJ (2003) Recall of the risks of forefoot surgery after informed consent. Foot Ankle Int 24(12):904-908

75. Stanley BM, Walters DJ, Maddern GJ (1998) Informed consent: how much information is enough? Aust N Z J Surg 68(11):788-791
76. Wadey V, Frank C (1997) The effectiveness of patient verbalization on informed consent. Can J Surg 40(2):124-128

77. Hopper KD, Zajdel M, Hulse SF et al (1994) Interactive method of informing patients of the risks of intravenous contrast media. Radiology 192(1):67-71

78. Jimison HB, Sher PP, Appleyard R et al (1998) The use of multimedia in the informed consent process. J Am Med Inform Assoc 5(3):245-256

79. Klima S, Hein W, Hube A et al (2005) Multimedia preoperative patient information. Chirurg 76(4):398-403 